\title{
(2) OPEN ACCESS \\ Assessing baseline practice and the implementation and efficacy of a novel device for medication security
}

\author{
Holly Young (D), Maryanne Z A Mariyaselvam, Vikesh Patel, \\ John Gibson, Emily Hodges, Natalie English, Robin Heij, \\ Gayathri Wijewardena, Darcy Pearson, Mark Blunt, Peter Young
}

Critical Care Unit, Queen Elizabeth Hospital King's Lynn NHS Foundation Trust, King's Lynn, UK

\section{Correspondence to}

Dr Holly Young, Critical Care Unit, Queen Elizabeth Hospital King's Lynn NHS Foundation Trust, King's Lynn, PE30 4ET, UK; hollyyoung101@googlemail.com

Received 1 September 2020 Revised 5 December 2020 Accepted 19 December 2020 Published Online First 21 January 2021

\section{Check for updates}

(C) Author(s) (or their employer(s)) 2021. Re-use permitted under CC BY-NC. No commercial re-use. See rights and permissions. Published by BMJ.

To cite: Young $\mathrm{H}_{\text {, }}$ Mariyaselvam MZA, Patel V, et al. BMJ Innov 2021;7:456462.

\section{INTRODUCTION}

Medication stored in hospitals, nursing homes, general practice surgeries or pharmacies must be handled, stored, dispensed and disposed of securely to protect patients and staff in accordance with part 4, section 13 of the Health and Social Care Act. ${ }^{1}$ These standards were revised in 2014, requiring the service provider to ensure 'proper and safe management of medicines'. ${ }^{2}$ The Care and Quality Commission (CQC) regulates compliance with this legislation by performing routine inspections of health and social care providers.

In hospitals, controlled drugs (CDs) such as sedative or opiate-based medications are stored within locked cupboards. ${ }^{3}$ Both CD cupboards and drug trolleys, when open, must be constantly supervised by staff and if left unattended securely locked, even for short periods. ${ }^{4}$

In reality, guideline compliance in busy healthcare environments can be challenging to achieve. During planned CQC visits, staff may be at their most compliant, yet in 2012 inspectors reported that 14\% of hospitals, $20 \%$ of nursing homes and $16 \%$ of residential homes across the UK failed to comply with the safe management of medicines standard during visits. ${ }^{5}$ Unlocked unattended medication trolleys have specifically been highlighted as issues of poor medication management in CQC reports, and in some cases this has affected care ratings of institutions and led to enforcement actions. ${ }^{67}$

Ultimately, failure of adherence to CQC recommendations can result in medication theft and tampering for which healthcare staff, who have easy access to drug cabinets, are often found to be culprits; and this is

\section{Summary box}

What are the new findings?

- The DruGuardian device improves compliance with UK law and Care Quality Commission guidance for safe medication management in healthcare facilities and deters medication theft or tampering.

- Baseline practice was poor. Cabinets were able to be covertly accessed on $60 \%$ of drug rounds and trusted staff could remove controlled drugs with $100 \%$ success.

- After introduction of the DruGuardian, correct attendance was improved by 20 fold. Non-attendance times decreased from 8 min to $22 \mathrm{~s}$ per day.

How might it impact on healthcare in the future?

- DruGuardians are easily introduced with minimal or no training, prevent drug theft and tampering in hospitals and ensure compliance with UK law.

highlighted in disciplinary hearings for the General Medical Council and Nursing and Midwifery Council. ${ }^{8-15}$ An anaesthetist sentenced to jail illustrates this, who used his old hospital pass to access and steal 2558 tablets of codeine from hospital cabinets, with costs totalling $£ 3360$. This occurred over 8 months with 75 different visits to the hospital, ${ }^{16}$ highlighting the ease with which recurrent theft may occur and the vulnerabilities of healthcare systems to medication diversion. ${ }^{17-19}$ Drug diversion is defined as the transfer of drugs from a lawful to an unlawful channel of distribution or use. ${ }^{20}$ This may only be the tip of the iceberg and there are likely many more incidents dealt with internally or remaining undetected. 

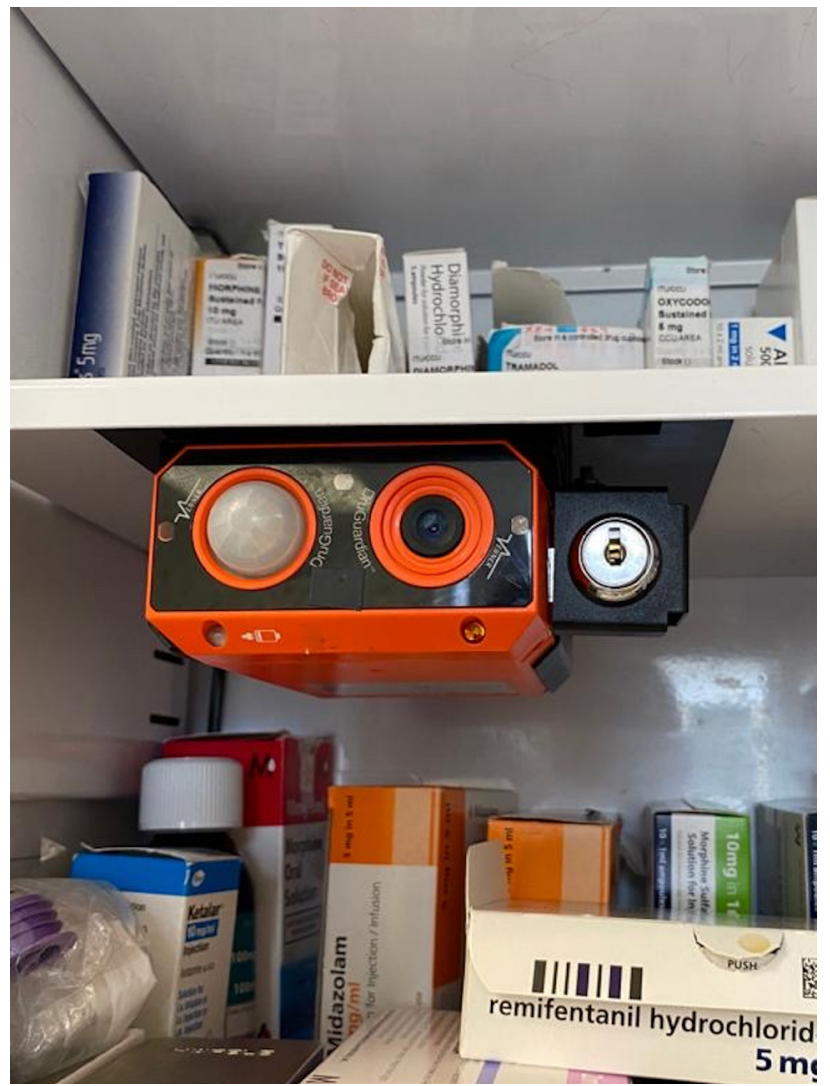

Figure 1 The DruGuardian device, demonstrating the camera, motion detector and light detector.

Although accurately determining drug theft frequency is challenging, a recent CQC report draws attention to the potential scope; during 2018/2019 there were 2899 unaccounted losses of CDs reported through the National Health Service (NHS) England national occurrence reporting tool. This averages eight detected losses daily across England, ${ }^{21}$ which is likely an underestimation as the reporting tool was new to several areas. Nearly half these reports involved CDs being lost, stolen or missing. ${ }^{22}$ Strengthening medication security systems is a necessary component in eliminating this problem, with a particular focus on incorporating systems-based solutions to deter, identify and intervene when drug diversion occurs. ${ }^{23} 24$

Drug diversion causes reputational damage to institutions, undermines public trust in the profession and results in adverse patient outcomes. ${ }^{25}$ Costs incurred range from medication prices to disciplinary procedures or addiction treatment costs, or at worst criminal investigations involving the police. An example is an estimated $£ 500000$ spent during the Stepping Hill Hospital drug tampering investigation. ${ }^{26}$

In recognition of these problems, the DruGuardian (Venner Medical International, St Helier, Jersey) has been developed. This is a self-contained, batterypowered device that can be retrofitted into any location and incorporates a light sensor, motion detector, crescendo buzzer and camera (figure 1). When placed inside a CD cupboard or drug trolley, the device detects light when the cabinet is open. Providing the drug cabinet is correctly attended, the motion detector is activated, and the device remains silent. However, when the cabinet is left opened and unattended for more than $40 \mathrm{~s}$ (interval set by the institution), a quiet alarm begins. Initially the alarm sounds softly, reminding staff to reattend, however if the cabinet continues to be unattended, the noise increases in volume until reattendance (triggering the motion detector) or closure (deactivating the light detector). This silences the alarm and resets the device, starting the cycle again. When the drug cabinet is correctly attended, the device remains silent and is unobtrusive for, or even completely unnoticed by the user.

While the drug cabinet is open, the device collects data including length of time the cabinet has been open for, number of times the alarm has been activated and length of alarm activation for each incident. The camera also captures time and date stamped photographs of anyone attending the cabinet, as a deterrent and to assist in investigations. The device is programmed to collect, record and create automated reports summarising data on an encrypted data card, which can be processed to audit behaviour and identify sources of criminal or poor practice. Preliminary research at our institution has demonstrated that the DruGuardian can modify staff behaviour through operant conditioning, a method of learning where desirable behaviours are reinforced through consequences. $^{27}$ The device reduced the number of times a drug trolley was left open and unattended from an average of 14 times a day in the absence of the alarm to 0.2 episodes per day when the alarm function was activated, without the need for explicit staff training. ${ }^{28}$ The present study aimed to expand on this preliminary research and further assess the effectiveness of the DruGuardian device in improving medication security and modifying staff behaviour more widely. Specifically, the implementation objectives were to achieve the installation of prototype devices across six hospital trusts in the surrounding region measuring baseline and post-intervention practice.

\section{METHODS}

Following the Integrated Research Approval System pathway it was determined by the host research and development committee that this study was a service evaluation involving staff undertaking their normal daily duties with all data collected anonymised and no patient involvement, and so did not require regional ethical approval. However, the six acute hospital trust implementation sites in the East of England each had individual formal institutional research and development approval sought and achieved. With input from the head of security, nursing director, chief executive and accountable officer, two proofs of concept studies were initially performed at one site. An implementation 
study was then conducted across the region. Prototype DruGuardians were used in all studies. For the purposes of the implementation study and to achieve protocol consensus across all sites, the photographic component of the device was disabled.

\section{Stealth study: determining ease of access to ward drug trolleys for a non-ward member}

During routine drug rounds on different general hospital wards, two critical care nurses unknown to the ward team attempted to substitute one medication for an identical version in a drug trolley on 20 occasions, without being detected. The nurses were chosen since they were members of the research team, and they were instructed to attempt to substitute a medication over a 10-minute time period, and record whether they 'passed' defined by successfully managing to substitute the medication without being identified, 'failed' meaning they were caught during their attempt or if there was 'no opportunity' during the 10-minute window, and thus did not attempt to substitute the medication and were also not identified in the process. They were instructed to record the time the attempt was made, the outcome and the ward on which the attempt was made. The percentage of time the nurses were successful in doing so while avoiding detection was recorded as the main outcome.

\section{Theft study: determining ease of access to morphine from CD cupboards in operating theatres}

DruGuardians were placed in all operating theatre CD cupboards with the camera activated. Although senior staff were aware of the study, those in control of the drug cupboard were not. A trusted senior staff member attempted to access and remove morphine on four occasions during the normal working day over a 2-week period without being detected by the operating department practitioners (ODPs). The trusted staff member was part of the research team, and he was instructed to attempt to remove a morphine ampoule without being detected on four occasions from CD cupboards in operating theatres. The percentage of time the trusted staff member was able to do this while avoiding detection was recorded. It was also recorded whether the device could accurately identify who had taken the morphine by retrospectively using the camera function.

\section{Implementation study}

Presentations were given to the security leads of all trusts at a Regional Security Management Systems Meeting. The DruGuardian was further discussed at each site locally to security, executive, pharmacy and ward staff. The six trusts were each given five devices and asked to place each of these inside a CD cupboard or drug trolley of their choice and record the location. A poster was placed inside cabinet doors informing staff that the DruGuardian was a new security device being trialled in their hospital and that the camera function was disabled.

Baseline study period: devices were installed in each trust over 4 months and had the alarm function switched off to record normal activity. The outcome was the total time the drug cabinet was left open (as detected by the light sensor) and unattended (as detected by the motion sensor) for greater than $50 \mathrm{~s}$.

Alarm study period: after this baseline study period, the alarm on the device was turned on internally at a site visit and set to activate after $40 \mathrm{~s}$ of the drug cabinet being left open and unattended. DruGuardians were placed inside the same cabinets for both the baseline and alarm study periods to improve behavioural comparisons. The outcome was the total time the drug cabinet was left open and unattended for greater than $50 \mathrm{~s}$ (the alarm begins at $40 \mathrm{~s}$, thereby allowing an additional $10 \mathrm{~s}$ to reattend). Identical data were recorded as for the baseline study, over a 2-month period.

Data were collected by devices and converted into a convenient report by a DruGuardian analysis programme. Percentage improvement in behaviour was calculated using the total time drug cabinets were left open and unattended for greater than 50 s per day in the baseline and alarm periods.

We invited all hospitals in the East of England critical care network to participate and six responded. Hospitals volunteered to participate in response to our invitation, thus we were unable to systematically produce a random sample, as we relied on the agreement of the individual sites. Our sample size of six trusts ranging from 300 to 750 beds in size however provided a varied spread of NHS activity and staff behaviour. Informal qualitative feedback was sought during the study period.

\section{RESULTS}

\section{Stealth study}

Nurses unknown to the ward team were successful in substituting like-for-like medications in drug trolleys during routine ward drug rounds 60\% (12/20 occasions) of the time without being detected. In the remaining $40 \%$ of cases, the nurses were unable to substitute medications, however their tampering attempt was not identified, nor were they challenged.

\section{Theft study}

The trusted senior staff member was able to successfully remove morphine from the CD cupboard 100\% (4/4 occasions) of the time, without being detected by the ODPs. During CD stock reconciliation at the end of the session, the discrepancies were discovered but it was not possible to identify the person responsible. However, on each occasion the DruGuardian photograph showed the perpetrator and the date and time of access was recorded. 
Table 1 Average time per day that drug cabinets were left open and unattended for greater than $50 \mathrm{~s}$ and the percentage improvement

\begin{tabular}{lcll}
\hline & \multicolumn{2}{l}{$\begin{array}{l}\text { Average time the drug cabinet } \\
\text { was left open and unattended } \\
\text { per day (min) }\end{array}$} & \\
\cline { 2 - 3 } Trust & Baseline & Alarm on & $\%$ improvement \\
\hline A & 1.81 & 0.03 & 98 \\
B & 15.63 & 1.78 & 89 \\
C & 39.88 & 1.87 & 95 \\
D & 3.03 & 0.19 & 94 \\
E & 15.96 & 0.53 & 97 \\
F & 6.89 & 0.37 & 95 \\
\hline
\end{tabular}

\section{Implementation study}

Six hospital trusts were recruited and 30 DruGuardians were used in the study periods. However, some data collected were erroneous and were discarded. Therefore, over the 4-month baseline period, 24 devices were successfully installed in 17 CD cupboards and 7 drug trolleys. In the alarm period there were data from 18 devices in CD cupboards and 9 in drug trolleys. DruGuardians were located in general ward drug trolleys and CD cupboards on general wards, emergency departments, operating theatres, maternity and ambulance services. The exact implementation period of devices varied between trusts during the baseline study due to the time taken for administration and installation. During the baseline period, a total of 1049 days of data were collected and in the alarm period, 1247 days of data were collected.

Across the six hospital trusts, the total time drug cabinets were left open and unattended for greater than $50 \mathrm{~s}$ during the baseline study period was $503048 \mathrm{~s}$ (8384 min), which is $479 \mathrm{~s}$ ( $8 \mathrm{~min}$ ) per day of device usage. During the alarm period, the total time drug cabinets were left open and unattended for greater than $50 \mathrm{~s}$ was $27590 \mathrm{~s}$ ( $459 \mathrm{~min})$, which is $22 \mathrm{~s}(0.36 \mathrm{~min})$ per day of device usage. This was a $95 \%$ improvement. Individual trust data demonstrated similar results and percentage improvements to the combined regional results (table 1). This was also seen when the data for $\mathrm{CD}$ cupboards and drug trolleys were analysed separately (table 2).

Table 2 Average time per day that drug cabinets were left open and unattended for greater than $50 \mathrm{~s}$ and the percentage improvement, sorted by drug cabinet type

Average time the drug cabinet was left open and unattended per day ( $\mathrm{min}$ )

\begin{tabular}{|c|c|c|c|}
\hline Drug cabinet & Baseline & Alarm on & $\%$ improvement \\
\hline CD cupboard & 7.06 & 0.17 & 98 \\
\hline Drug trolley & 18.67 & 1.90 & 90 \\
\hline
\end{tabular}

$\mathrm{CD}$, controlled drug.
Qualitative feedback included that one department reported that the device was no longer working, despite alarming after $40 \mathrm{~s}$ when tested. Another unintended result was a study hospital requesting photographs from the device to investigate a drug discrepancy. Informal feedback included that 'staff are much more aware to not leave the drug trolley open and unattended' and 'I had forgotten all about the DruGuardian being in the trolley until it sounded, so it definitely works'.

\section{DISCUSSION}

The stealth study demonstrates the ease with which nurses unknown to the ward team can gain unfettered access to a supervised trolley during drug rounds. The theft study similarly demonstrates that senior staff can remove CDs undetected in operating theatre settings. Drug diversion can result in patients receiving diluted, different or no medication. ${ }^{29}{ }^{30}$ Reports also detail outbreaks of healthcare-associated infections including hepatitis $\mathrm{C}$ and bacterial pathogens as a direct result of drug diversion and subsequent drug contamination which may be particularly problematic with multidose vials. $^{31-33}$ These outbreaks highlight vulnerabilities in the prevention, detection and response to drug diversion, and the Centers for Disease Control and Prevention states that there should be active monitoring systems in place to prevent and detect diversion. ${ }^{29}$ The DruGuardian may have a role in this respect.

A potential limitation of the theft study was using a senior member of staff to remove a morphine ampoule, as operating theatre staff may supervise them less closely. It is perhaps the need for the trust that one must have in staff that creates a vulnerability in the system and provides opportunity for individuals. This fundamentally highlights why photography is vital. In the event of a CD discrepancy, a single photographed attendance at the cabinet of the senior staff member may raise questions, however drug theft tends to be recurrent and in the present study at all four cabinets with a drug discrepancy the same staff member was identified at each cabinet at a time which would implicate him.

When the DruGuardian was implemented across six hospital trusts, a 95\% improvement was seen. This reduction was also seen when results were analysed by trust and drug cabinet type (drug trolleys or CD cupboards), demonstrating that the device had similar improvement effects across a range of hospitals, wards and drug cabinets. The device demonstrated a strong effect on staff behaviour and by reducing the time that drug cabinets are left open and unattended, it may improve medication safety and act as a deterrent to theft and tampering.

During a hospital visit by the study team, an incidental finding was that one department reported that the device was no longer working. The drug cabinet containing the device in question was thus tested by leaving it open and 
unattended, and after $40 \mathrm{~s}$, the device started alarming and working normally. The nurses had subconsciously changed their behaviour and hence had not heard any alarms and thought the device was malfunctioning. This demonstrates the DruGuardian's role as a non-disruptive and non-obtrusive behaviour modifier, with the alarm alerting staff to an error and modifying subsequent behaviour by operant conditioning, rather than further education or training efforts.

Training has been demonstrated to be less effective in modifying behaviour than the alarm system in another study using the DruGuardian. This demonstrated that with education and training interventions alone, episodes of drug cabinets being left open and unattended dropped from 14 at baseline to 13 per day, compared with an average of 0.2 episodes per day when the alarm function was activated. ${ }^{28}$ Targeting education and training have been ranked lowest in terms of the hierarchy of intervention effectiveness when trying to prevent errors in healthcare whereas engineered solutions are the highest. ${ }^{34}$ Additionally, nurses can often be distracted by patients, other healthcare staff or the telephone and this may not always allow them to fully comply with guidelines. One study highlighted that nurses were interrupted on average 26 times during a drug administration round. ${ }^{35}$ In the context of busy clinical environments, further education and training may be of limited benefit in improving compliance, and also may be forgotten over time and with staff turnover.

One of the study hospitals contacted the study team urgently requesting time and date stamped photographs collected by a device to investigate a drug discrepancy. They were reminded that for the purposes of the study, the camera was switched off during the implementation period. This unintended effect highlights the necessity of the camera function to act as a deterrent to drug theft. Although manual counting systems identify discrepancies in the inventory of medications, this has been criticised for both the time-consuming nature and the inability to identify perpetrators. ${ }^{36}$ Suspected drug thefts can be investigated with time and resource efficiency if an accurate indication of all individuals attending cabinets exists. Indeed, one study has demonstrated that a camera attached to a drug cupboard can accurately capture date and time stamped images. ${ }^{37}$

Informal feedback from staff during the implementation study has facilitated further refinement of the DruGuardian with comments such as 'staff are much more aware not to leave the drug trolley open and unattended' and 'I had forgotten all about the DruGuardian being in the trolley until it sounded, so it definitely works', highlighting both the convenience and efficacy of the device. Staff also reported that the alarm pitch and volume was suitable and did not affect patients when they were sleeping. Some staff commented that the motion detector should be more sensitive, so that they had greater freedom to move around without the device thinking that the drug cabinet was unattended.
In light of this, the device has been modified to now include a secure docking system, very wide-angle camera lens, more sensitive motion detector, and larger data storage and battery capacity. Nevertheless, when new practice is introduced in any environment, there are often barriers preventing its uptake, such as lack of senior support, resistance from staff or the cost of new technology. ${ }^{38}$ Indeed, informal feedback during the study revealed that many nurses initially felt that they were being watched by the camera inside the drug cabinet. However, once nurses had the purpose of the camera explained to them and its role in protecting them from false accusations of theft (as the camera is able to photograph a true perpetrator), most changed their opinion of the DruGuardian and subsequently wanted the device in their cupboards.

\section{CONCLUSIONS}

The Health and Social Care Act requires healthcare providers to manage and store medications safely and securely. Compliance to this is monitored by the CQC and a key requirement is that drug cabinets in healthcare settings are never left open and unattended, something which has proven difficult to achieve nationally. The DruGuardian is a device which alerts staff when a drug cabinet has been opened and left unattended. It creates a data record of activity, compliance and a photographic audit trail of who has accessed the cabinet. The stealth, theft and implementation studies demonstrate that the DruGuardian can support staff and institutions in their safe management of medicines and help to prevent theft or tampering of medications by dramatically reducing the time that drug cabinets are left open and unattended.

Contributors HY, MZAM and VP drafted the work, and this was then revised critically by all authors. All authors had final approval of the version to be published and are jointly accountable for all aspects of the work. The conception and design of the work was led by PY, JG, MB, RH and MZAM. The stealth study was conducted by EH and NE, and the theft study by DP. The implementation study was conducted by MZAM, GW and NE.

Funding We report grants from Eastern Academic Health Science Network.

Competing interests PY is the inventor named on patents and does consultancy work for Venner Medical. There is an expectation that any royalties generated will be shared among the other authors and his institution. There is a commitment in writing that the Queen Elizabeth Hospital Kings Lynn will receive a proportion of the royalties, alongside approximately 10 other contributors, should they emerge. The proportions depend on ongoing engagement. HY is the daughter of PY. MZAM and PY are married. MB and JG report non-financial support from Venner Medical, outside the submitted work.

Patient consent for publication Not required.

Provenance and peer review Not commissioned; externally peer reviewed.

Open access This is an open access article distributed in accordance with the Creative Commons Attribution Non Commercial (CC BYNC 4.0) license, which permits others to distribute, remix, adapt, build upon this work non-commercially, and license their derivative works on different terms, provided the original work is properly cited, appropriate credit is given, any changes made indicated, 
and the use is non-commercial. See: http://creativecommons.org/ licenses/by-nc/4.0/.

\section{ORCID iD}

Holly Young http://orcid.org/0000-0002-4631-6700

\section{REFERENCES}

1 National Health Service, England, Social Care, England, Public Health, England. The health and social care act 2008 (regulated activities) Regulations 2010. No. 781 Statutory instruments, 2010. Available: http://www.legislation.gov.uk/ uksi/2010/781/pdfs/uksi_20100781_en.pdf [Accessed Jun 2020].

2 National Health Service, England, Social Care, England, Public Health, England. The health and social care act 2008 (regulated activities) regulations 2014. No. 2936 statutory instruments, 2014. Available: http://www.legislation.gov.uk/ uksi/2014/2936/pdfs/uksi_20142936_en.pdf [Accessed Jun 2020].

3 Dangerous Drugs, England, Dangerous Drugs, Scotland. The controlled drugs (supervision and management of use) regulations 2013. No. 373 statutory instruments, 2013. Available: http://www.legislation.gov.uk/uksi/2013/373/pdfs/ uksi_20130373_en.pdf [Accessed Jun 2020].

4 Griffiths M. Safe use of drug trolleys. Nurs Stand 2016;31:28.

5 Care Quality Commission. Medicines in health and adult social care, 2019. Available: https://www.cqc.org.uk/sites/default/files/ 20190605_medicines_in_health_and_adult_social_care_report. pdf [Accessed Jun 2020].

6 Care Quality Commission. Market report issue 1, 2012. Available: https://www.cqc.org.uk/sites/default/files/documents/ 20120626_cqc_market_report_issue_1_for_website_final_0. pdf [Accessed Jun 2020].

7 Care Quality Commission. Mental health Bulletin, 2015. Available: https://www.cqc.org.uk/sites/default/files/20150915 cqc_mental_health_bulletin_sept15.pdf [Accessed Jun 2020].

8 Nursing and Midwifery Council. Conduct and competence Committee substantive hearing 5 may 2017. Available: https:// www.nmc.org.uk/globalassets/sitedocuments/ftpoutcomes/ 2017/may-2017/reasons-cooper-cccsh-57276-20170505.pdf [Accessed Jun 2020].

9 Nursing and Midwifery Council. Conduct and competence Committee substantive hearing 14 may 2018. Available: https://www.nmc.org.uk/globalassets/sitedocuments/ ftpoutcomes/2018/may-2018/reasons-heller-ftpcsh-5175420180514.pdf [Accessed Jun 2020].

10 Nursing and Midwifery Council. Fitness to practice Committee substantive meeting 5 September, 2018. Available: https:// www.nmc.org.uk/globalassets/sitedocuments/ftpoutcomes/ 2018/september-2018/reasons-jackson-ftpcsm-5997020180905.pdf [Accessed Jun 2020].

11 Nursing and Midwifery Council. Fitness to practice Committee substantive hearing 21-25 October 2019. Available: https:// www.nmc.org.uk/globalassets/sitedocuments/ftpoutcomes/ 2019/october-2019/reasons-miller-ftpcsh-55801-20191025.pdf [Accessed Jun 2020].

12 Nursing and Midwifery Council. Fitness to practice Committee substantive meeting 19-20 September 2018. Available: https:// www.nmc.org.uk/globalassets/sitedocuments/ftpoutcomes/ 2018/september-2018/reasons-randall-ftpcsm-6235320180920.pdf [Accessed Jun 2020].
13 Nursing and Midwifery Council. Conduct and competence Committee substantive hearing 19 June 2015 and 16 July 2015. Available: https://www.nmc.org.uk/globalassets/ sitedocuments/ftpoutcomes/2015/jul/reasons-rennebach-cccsh042880-20150716.pdf [Accessed Jun 2020].

14 Nursing and Midwifery Council. Fitness to practise Committee substantive hearing 18-21 September 2017. Available: https:// www.nmc.org.uk/globalassets/sitedocuments/ftpoutcomes/ 2017/sept-2017/reasons-wood-ftpcsh-50324-57416-20170921. pdf [Accessed Jun 2020].

15 Ling D. Medical practitioners Tribunal service. Available: https://www.mpts-uk.org/-/media/mpts-rod-files/dr-suzanneling-13-mar-2020.pdf [Accessed Jun 2020].

16 Dyer C. Anaesthetist is jailed after stealing codeine from hospital where he no longer worked. BMJ 2017;359:j4841.

17 Higgins P. Northern Ireland nurse spared jail after stealing pills to feed painkiller and sedative addictions, 2017. Available: https://www.belfasttelegraph.co.uk/news/northern-ireland/ northern-ireland-nurse-spared-jail-after-stealing-pills-to-feedpainkiller-and-sedative-addictions-35416690.html [Accessed Jun 2020].

18 Nugent C. Doctor stole painkillers from Colchester Hospital". Colchester Gazette. Available: https://www.gazette-news.co.uk/ news/18165978.doctor-stole-painkillers-colchester-hospital/ [Accessed Jun 2020].

19 Kennedy R, Boyd M. Nurse on children's ward filmed swigging painkillers from medicine cupboard, 2019. Available: https:// www.mirror.co.uk/news/uk-news/nurse-childrens-ward-filmedswigging-19185656 [Accessed Jun 2020].

20 National Conference of Commissioners of Uniform State Laws. Uniform controlled substances act 1994. Available: https://www.uniformlaws.org/HigherLogic/System/ DownloadDocumentFile.ashx?DocumentFileKey=34039f08ab0d-24fd-d349-b8f58e81b281 [Accessed Nov 2020].

21 Care Quality Commission. The safer management of controlled drugs: annual update 2018. Available: https://www. cqc.org.uk/sites/default/files/20190708_controlleddrugs2018_ report.pdf [Accessed Jun 2020].

22 Robinson J. Open to abuse: gaps highlighted in the controlled drug system. The Pharmaceutical Journal 2019 https://www. pharmaceutical-journal.com/news-and-analysis/features/opento-abuse-gaps-highlighted-in-the-controlled-drug-system/ 20207251.article

23 Berge KH, Dillon KR, Sikkink KM, et al. Diversion of drugs within health care facilities, a multiple-victim crime: patterns of diversion, scope, consequences, detection, and prevention. Mayo Clin Proc 2012;87:674-82.

24 Fan M, Tscheng D, Hamilton M, et al. Diversion of controlled drugs in hospitals: a scoping review of contributors and safeguards. J Hosp Med 2019;14:419-28.

25 Berge KH, Lanier WL. Bloodstream infection outbreaks related to opioid-diverting health care workers: a cost-benefit analysis of prevention and detection programs. Mayo Clin Proc 2014;89:866-8.

26 Thompson D. Revealed: $£ 500 \mathrm{k}$ bill for security boost after poison probe at stepping Hill Hospital, 2012. Available: https://www.manchestereveningnews.co.uk/news/greatermanchester-news/revealed-500k-bill-for-security-boost-680066 [Accessed Jun 2020].

27 Skinner BF. The behavior of organisms: an experimental analysis. Oxford, England: Appleton-Century, 1938.

28 Hodges E, Pearson D, Moondi P, et al. Using an alarm to improve drug trolley safety. Nurs Times 2015;111:20-1. 
29 Centers for Disease Control and Prevention. Drug diversion. Available: https://www.cdc.gov/injectionsafety/drugdiversion/ index.html [Accessed Jun 2020].

30 Forliti A. Man up': Nurse charged with taking patients' drugs, 2011. Available: https://www.seattletimes.com/seattle-news/ health/man-up-nurse-charged-with-taking-patients-drugs/ [Accessed Jun 2020].

31 Njuguna HN, Stinson D, Montgomery P, et al. Hepatitis C Virus Potentially Transmitted by Opioid Drug Diversion from a Nurse - Washington, August 2017-March 2018. MMWR Morb Mortal Wkly Rep 2019;68:374-6.

32 Schaefer MK, Perz JF. Outbreaks of infections associated with drug diversion by US health care personnel. Mayo Clin Proc 2014;89:878-87.

33 Wasiura J, Segal BH, Mullin KM. Cluster of Sphingomonas paucimobilis Bacteremias Linked to Diversion of Intravenous Hydromorphone. N Engl J Med 2019;381:584-5.
34 Cafazzo JA, St-Cyr O. From discovery to design: the evolution of human factors in healthcare. Healthc Q 2012;15 Spec No:24-9.

35 Relihan E, O'Brien V, O'Hara S, et al. The impact of a set of interventions to reduce interruptions and distractions to nurses during medication administration. Qual Saf Health Care 2010;19:e52.

36 Perry JC, Vandenhouten CL. Drug diversion detection. Nurs Manage 2019;50:16-21.

37 Mariyaselvam M, Pearson D, Moondi P, et al. The limpet controlled drug cabinet alarm and camera. Crit Care 2014;18:P2.

38 NHS England National Institute for Health and Clinical Excellence. How to change practice: understand, identify and overcome barriers to change; 2007: 1-48. https://www.nice. org.uk/media/default/about/what-we-do/into-practice/supportfor-service-improvement-and-audit/how-to-change-practicebarriers-to-change.pdf [Accessed Jun 2020]. 